\title{
Melhoria organizacional na produção de bezerros de corte a partir dos centros de custos
}

\section{Ricardo Pedroso Oaigen ${ }^{1}$, Júlio Otávio Jardim Barcellos ${ }^{2}$, Luciana Fagundes Christofari ${ }^{1}$, José Braccini Neto ${ }^{2}$, Tamara Esteves de Oliveira ${ }^{3}$, Ênio Rosa Prates ${ }^{2}$}

\footnotetext{
${ }^{1}$ Curso de Pós-Graduação em Zootecnia, Faculdade de Agronomia - UFRGS.

2 Departamento de Zootecnia, Faculdade de Agronomia - UFRGS.

${ }^{3}$ Curso de Graduação em Medicina Veterinária - UFRGS.
}

RESUMO - O objetivo neste trabalho foi evidenciar a importância do custo de produção na pecuária de cria, descrevendo uma metodologia padronizada que consiga mensurar o custo de produção de bezerros de corte e, simultaneamente, validar o método em um sistema de produção. Dentro deste contexto, neste trabalho discute-se, inicialmente, a relevância da implantação da metodologia dos centros de custos como suporte à tomada de decisão, devido à necessidade de uma análise segmentada dos processos em sistemas de produção pecuários especializados na cria. As etapas para implantação deste método são descritas. Um sistema de produção, característico da Região Sul do Brasil, foi definido a partir de indicadores técnicos relatados em revisões bibliográficas. Foi simulada a aplicação desta metodologia no sistema em questão, no qual se visualizaram os custos de produção dos diferentes centros produtivos: touros, vacas de cria, recria das novilhas e desmame dos bezerros, possibilitando compreender o impacto de determinados processos e/ou tecnologias no sistema. Conseqüentemente, calcular o custo de produção de bezerros de corte a partir da utilização da metodologia dos centros de custos, mostrou-se factível de utilização em sistemas de produção baseados em pecuária de cria.

Palavras-chave: gerenciamento de custos, gestão rural, pecuária de cria, sistemas de produção

\section{Organizational improvement in the beef calves production from of the cost centers}

\begin{abstract}
The production cost in cow-calf was designed by a standard methodology that can be able to measure the production cost of calves and, simultaneously to validate the method in a production system. Within this context, the present paper discusses, initially, the relevance of the implementation of methodology in cost centers as a support decisionmaking, due to the need for a segmented analysis of the processes, specialized in cow-calf production systems. The stages for implementation of this method are described. A production system, typical of the Southern of Brazil, was defined from technical indicators reported in reviews. It was simulated the application of this methodology of the subjected system, where it was viewed the production costs of the different productive centers: bulls, cows, rearing of heifers and weaning of calves, enabling to understand the impact that determinates process and/or technologies bring on to the system. Consequently, to calculate the production cost of calves from the methodology based on the cost centers was feasible to be used in production systems based on cow-calf.
\end{abstract}

Key Words: agricultural management, costs management, cow-calf, production systems

\section{Introdução}

A pecuária de cria é definida como a principal etapa de produção da bovinocultura de corte, que constitui a base de sustentação da atividade (Rovira, 1996). Consideráveis aumentos na produtividade dos rebanhos de cria foram obtidos nos últimos anos, resultado da inovação tecnológica gerada pela pesquisa desenvolvida nas diferentes instituições do País, permitindo a geração e aplica- ção de novos processos de produção (Barcellos et al., 2004). No entanto, nota-se que, na medida em que ganhos de produção e produtividade foram alcançados, a situação econômica dos sistemas de produção piorou, fazendo com que muitos produtores saíssem da atividade. Em razão de ter sido um negócio lucrativo e atraente no passado, o setor foi avesso às rupturas, mantendo-se como uma atividade reconhecidamente conservadora e de forte patrimonialismo (Vitorino Filho, 2002). 
Este cenário agravou-se após a implantação do plano real, na década de 90 , quando a estabilização econômica e a queda nos ganhos especulativos, aliados à globalização da economia mundial, levaram o setor pecuário brasileiro a enfrentar dificuldades. A redução da margem de lucro, o aumento da concorrência e as exigências por produção de carne de qualidade e de menor custo tornaram a pecuária de ciclo longo e com baixa produtividade e qualidade de produto economicamente inviável.

Na realidade, apesar destas dificuldades, muitas propriedades rurais ainda são gerenciadas de forma empírica, sem condições de conhecer o custo de produção, como uma das principais informações de suporte à tomada de decisão. Portanto, fortalecer a gestão empresarial, pelo conhecimento de informações estratégicas, é uma das grandes medidas a serem implementadas em uma fazenda de gado de corte. A gestão do negócio torna o crescimento do empreendimento rural viável, fortalecendo-o para os momentos de crise, além de prepará-lo para novas oportunidades (Oaigen et al., 2006).

Segundo Bornia (2002), a contabilidade dos custos passará a desempenhar um importante papel como sistema de informações gerenciais, obtendo lugar de destaque nas empresas. A conjuntura atual em que as empresas rurais estão inseridas é altamente dinâmica, refletindo na quantidade e qualidade das informações necessárias à gestão dos empreendimentos. Segundo Corah (1995), um problema citado por produtores rurais e profissionais que atuam no setor agropecuário norte-americano é a falta de padronização nas análises técnico-financeiras das propriedades, causando problemas no entendimento e uso das informações geradas.

Portanto, os sistemas gerenciais devem ser padronizados, objetivando a comparação entre os indicadores produtivos e financeiros. Assim, a definição de um método padrão de análise de custo auxilia na uniformidade das informações e dos indicadores gerados, bem como possibilita a comparação de diferentes sistemas de produção.

Este trabalho foi conduzido com o objetivo de evidenciar a importância do custo de produção na pecuária de cria, descrevendo uma metodologia padrão capaz de calcular o custo de produção de bezerros de corte e, simultaneamente, aplicar o método em um sistema de produção.

\section{Material e Métodos}

Foi realizada uma revisão bibliográfica em artigos científicos publicados em periódicos nacionais e internacionais, livros das áreas de economia, administração, contabilidade, engenharia da produção e ciências agrárias, anais de eventos e cursos extracurriculares, assim como indicações de especialistas que atuam na área de gerenciamento de custos e pecuária de corte, para definir, entre as metodologias existentes, qual seria a mais aplicável no cálculo do custo de produção de bezerros de corte.

Entre os principais métodos de custos existentes na literatura, destacam-se o custo-padrão, custeio baseado em atividades (ABC) e centros de custos. O custeio baseado em atividades é contemporâneo e basicamente gerencial; comparativamente ao método do custo-padrão, apresenta maior qualidade, pois, além de ser uma ferramenta gerencial que permite avaliar processos e atividades dentro do ciclo de produção pecuário, é também distribuidor dos custos aos produtos. No entanto, em comparação ao método dos centros de custos, especificamente na pecuária de cria, torna-se mais oneroso e de difícil implantação pela excessiva complexidade dos processos requeridos, sendo necessário o estabelecimento de critérios detalhados dentro do sistema de produção, visando à apuração das informações. Porém, ocasiona um rateio muito preciso dos custos indiretos, apesar da subjetividade sempre presente (Figueiredo, 1996; Bornia, 2002).

A escolha da metodologia dos centros de custos ocorreu pela fácil aplicação em sistemas de produção de cria, aliado à possibilidade de analisar a eficiência dos diferentes núcleos produtivos dentro da empresa rural. Este método é muito difundido no Brasil, especialmente em outros setores, caracterizando-se como um sistema gerencial simples de implantação, o que favorece a análise dos resultados. Está centrado na subdivisão da empresa em centros de custos, também denominados departamentos produtivos (Santos \& Marion, 1993). A partir da definição da metodologia proposta, foram feitas inicialmente considerações seguidas pela aplicação em um sistema de produção de pecuária de cria.

Na bovinocultura de corte, a fase de cria é aquela destinada à produção do bezerro, constituída por touros, vacas de cria, novilhas de reposição (um ano de idade), novilhas para o primeiro acasalamento (dois anos de idade) e bezerros, com pequenas variações dependendo do sistema de produção. Consta na Figura 1 a composição média, em categorias, de um rebanho de cria, cujos índices produtivos são: taxa de desmama (70\%), idade ao primeiro acasalamento (dois anos), relação touro/vaca (1/20) e taxa de reposição de fêmeas (30\%). Esta é uma composição média, encontrada em trabalhos científicos relacionados a rebanhos de cria (Lobato, 1999; Oliveira et al., 2006).

Na Figura 2 são apresentadas as etapas para implantação do método dos centros de custos dentro de um sistema de produção. 


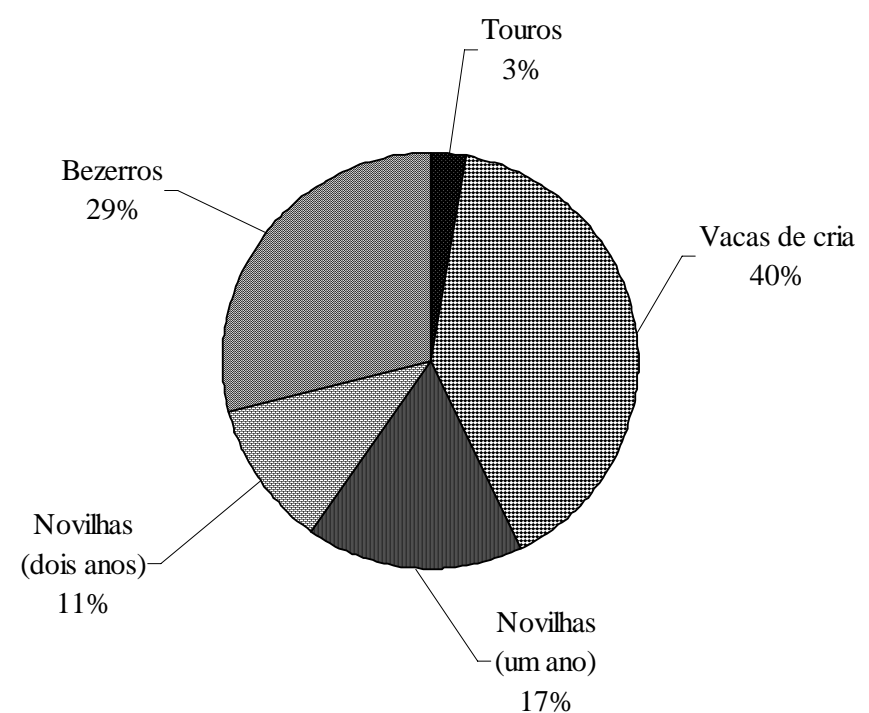

Figura 1 - Estrutura de um rebanho de cria em categorias.
A etapa A refere-se ao diagnóstico do sistema de produção, em que, a partir da realidade exposta, uma seqüência de etapas na gestão da empresa é implantada, a fim de visualizar os diferentes processos. Para se ter um bom diagnóstico, é fundamental que a administração da fazenda disponha e faça uso de um eficiente sistema de controles. O treinamento da mão-de-obra ocorre após o diagnóstico, sendo fundamental a conscientização dos colaboradores quanto à importância do estabelecimento de controles gerenciais.

Na etapa B são identificadas as atividades produtivas que sustentam a produção de bezerros, denominados centros de custos. Dentro desta etapa, são definidos o plano de contas gerencial e os critérios de rateio. Posteriormente, a coleta de dados - momento de registro e compilação das informações - deve ser padronizada e sistemática, utilizando-se instrumentos como planilhas, cadernetas ou

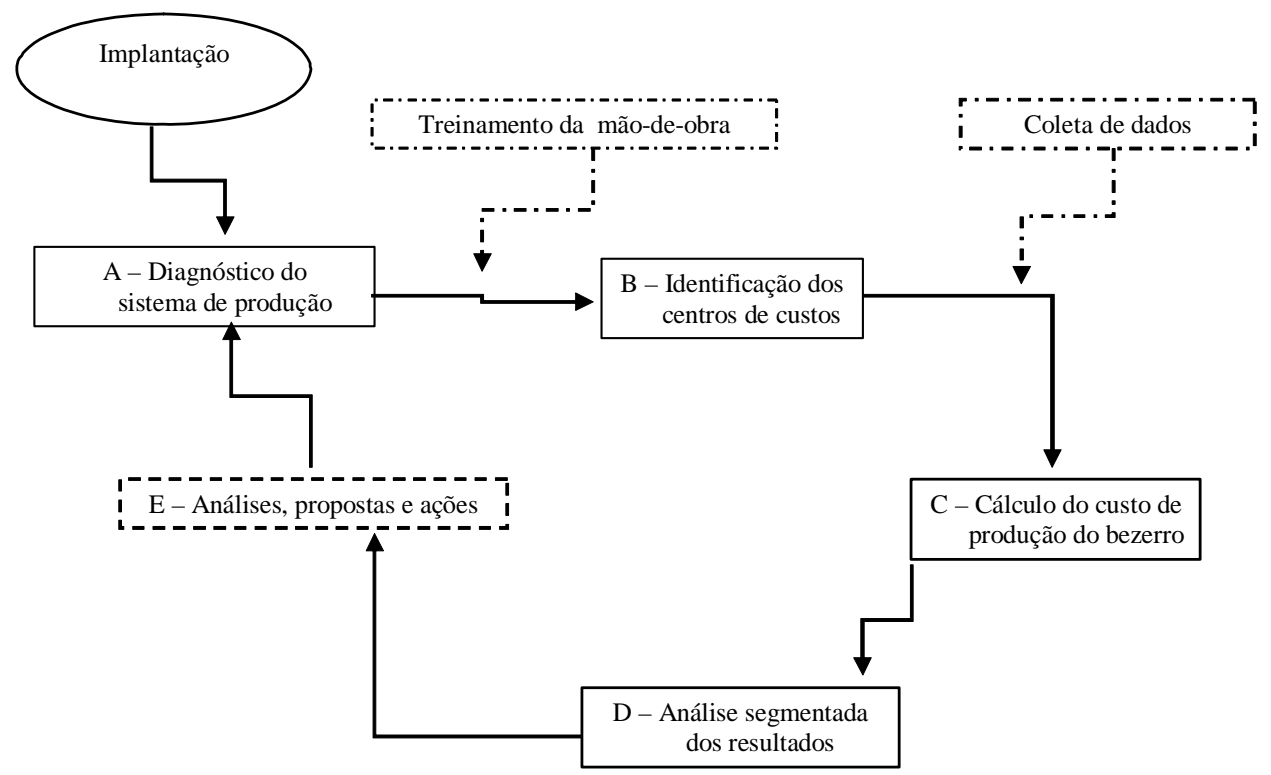

Figura 2 - Fluxograma dos centros de custos.

fichas de coleta de dados. Falhas e distorções nesta fase incorrerão em avaliações e análises que não refletirão a verdadeira realidade do negócio, pela obtenção de valores equivocados, prejudicando a tomada de decisões. O sistema representa um conduto que coleta dados em diversos pontos, processa-os e emite, com base neste, relatórios na outra extremidade (Bonaccini, 2002; Vitorino Filho, 2002).

Todas as despesas e custos mensuráveis necessários para a produção devem ser considerados na determinação do custo de produção. Se assim feito, o produtor rural ou técnico poderá monitorar as despesas mensalmente, realizando uma análise mais detalhada, objetivando encontrar possíveis pontos de estrangulamento.
A coleta de dados ocorre constantemente, entretanto, é importante a definição de um ciclo produtivo que englobe os lançamentos de todas as despesas, custos e receitas do período a ser analisado. Na aplicação da metodologia dos centros de custos, para a produção de bezerros, foi arbitrado que o ciclo anual englobe o período de $1^{\circ}$ de julho a 30 de junho, pois os bezerros nascidos na primavera normalmente já foram desmamados e comercializados, supondo que as vendas ocorram em abril. No entanto, deve ser considerado que podem ocorrer variações nas datas, permitindo análises em qualquer época do ciclo produtivo.

A etapa $C$ refere-se ao processamento dos dados, por meio de planilhas eletrônicas ou sistemas informatizados 
adaptados à metodologia, e pode ser feita por funcionários treinados da própria empresa ou por terceiros de empresas de consultoria. Neste trabalho os dados foram processados em planilhas eletrônicas do MS-Excel. Nas etapas D e E, são feitas análises dos resultados obtidos por este método, por intermédio de gráficos e tabelas, impressos em relatórios técnicos. Na etapa $D$ verifica-se a eficiência e o desembolso atribuído a cada centro de custo. Na última etapa, o gestor estará apto a tomar decisões com o objetivo de minimizar custos e, conseqüentemente, maximizar a eficiência técnica, propondo melhorias a partir de indicadores técnicos e econômicos.

\section{Resultados e Discussão}

A metodologia fundamenta-se na análise do sistema de produção pecuário, a partir da identificação dos centros de custos diretos ou indiretos. Segundo Figueiredo (1996), entende-se por centro de custos de uma empresa qualquer unidade de agregação de custo realizando uma atividade ou um conjunto de atividades que detém certas similaridades. É fundamental configurar um sistema de contabilidade gerencial e de análises do sistema, por lotes de animais, em centros de custos distintos (Martins, 2003).

Quando a pecuária de corte é baseada no ciclo completo, ou seja, detém todas as fases da produção, os diferentes segmentos - cria (produção do bezerro), recria (desenvolvimento do macho e da fêmea) ou terminação (engorda de machos e fêmeas) - caracterizam-se como centros de custos dentro desta atividade. No entanto, também podem existir centros de custos dentro de cada segmento. Deste modo, na cria, a recria da novilha ou o desmame dos bezerros podem ser definidos como centros de custos.

A característica principal deste método é a divisão da organização em centros de custos. Os custos são alocados aos centros, por meio de bases de distribuição e, depois, repassados aos produtos finais (Figura 3).

Existem diferentes classificações dos centros de custos. Neste trabalho, foram divididos em custos diretos e indiretos. Os custos diretos são aqueles atribuídos diretamente aos produtos e os indiretos são os que prestam apoio aos centros diretos e serviços à empresa em geral. Segundo Bornia (2002), quando o centro é direto, é possível obter boa alocação dos custos aos produtos; um exemplo é o custo da técnica de inseminação artificial, que pode ser apropriado diretamente para o centro de custos das vacas de cria. Entretanto, quando o centro é indireto, por exemplo, o transporte do administrador, isso não ocorre, sendo mais fácil e lógico relacionar seus custos a outros centros do que diretamente com os produtos. Neste caso é necessário realizar um rateio entre as atividades que indiretamente se beneficiam com esta despesa ou custo.

Os principais centros de custos diretos são o desmame, a recria de novilhas, vacas de cria e touros (Figura 3). Os indiretos são os bens (máquinas, implementos, benfeitorias e veículos) e a administração da propriedade. O critério para

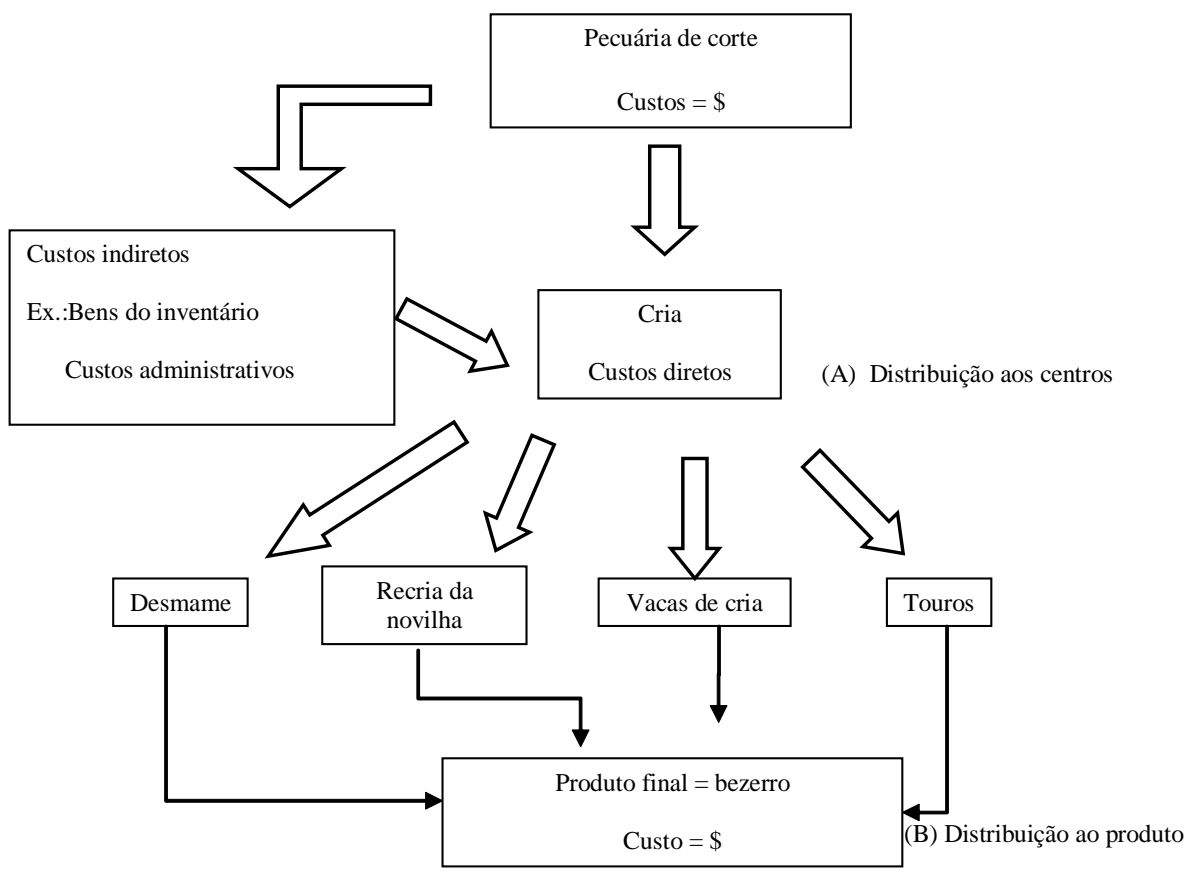

Figura 3 - Distribuição dos centros de custos. 
o rateio das despesas comuns a vários centros foi realizado a partir da estrutura do rebanho (Tabela 1) constituído por unidades animais (1 UA = $450 \mathrm{~kg}$ ) (Santos \& Marion, 1993). Deve ser acrescentado que os dados utilizados na definição deste rebanho e na base para o rateio estão de acordo com os percentuais descritos no Material e Métodos (Figura 1). Para o centro de custos da recria de novilhas, foram consideradas as novilhas de um e dois anos, portanto, são custos dos processos de duas categorias de animais.

O percentual de rateios recebido por centro de custo foi correlacionado à estrutura de rebanho. Por isto, os centros das vacas de cria e novilhas recebem a maior parte dos custos indiretos de produção, pois somados representam 80,2\% do percentual das UA do rebanho em análise. Desta maneira, torna-se importante alocar os custos de produção, dentro do possível, diretamente aos centros, minimizando o rateio, tornando mais correto o valor respectivo a cada centro. Neste sentido, a metodologia dos centros de custos permite uma alocação mais apropriada das despesas dentro do seu centro, o que representará diretamente o custo de produção dos processos ou do centro (Figueiredo, 1996; Bornia, 2002). Portanto, a contabilidade de custos, por essa metodologia, constitui um novo suporte para a tomada de decisões.

A aplicação da metodologia parte da definição de dois conceitos, o custo total de produção (CT) e o custo operacional (CO). Para o custo total de produção, devem ser considerados os custos fixos e variáveis, somados à remuneração da terra e capital, conforme a equação (a):

(a): Custo total $(\mathrm{CT})=$ custo fixo $(\mathrm{CF})+$ custo variável

(CV) + temuneração da terra e capital

Segundo Lopes \& Carvalho (2000), o método do custo operacional de produção surgiu da dificuldade de se avaliarem itens como remuneração da terra e do capital e prólabore do empresário. Este método desenvolvido pelo Instituto de Economia Agrícola do Estado de São Paulo refere-se ao custo de todos os recursos de produção que exigem desembolso por parte do produtor, como mão-deobra, alimentação, sanidade, reprodução, impostos, despesas diversas, aquisição de animais, entre outros. A depreciação compõe o custo operacional de produção. A equação para calcular é a seguinte (b):

(b): custo operacional (CO) = custo desembolsado (CD)

$$
+ \text { depreciação (D) }
$$

Segundo a metodologia proposta pelo CEPEA \& CNA (2006), o custo operacional pode ser subdividido em efetivo, não constando a depreciação e o total, que inclui depreciação e investimentos em geral, como reforma de pastagens e aquisição de máquinas.

A partir dos pressupostos teóricos, na cria, o custo unitário do bezerro desmamado será calculado pela equação (c), que pode ser utilizada para obtenção do custo unitário total (CT) ou custo unitário operacional (CO):

custo total (CT) ou custo operacional (CO)

(c): custo unitário do $=$ bezerro (CUB)

$\mathrm{n}$ o bezerros desmamados

O custo por quilo desmamado (C/kg) é calculado pela equação (d):

custo total (CT) ou custo operacional (CO)

(d): $\mathrm{C} / \mathrm{kg}=$

$\mathrm{n}$ - bezerros desmamados $\mathrm{x}$ peso médio

A determinação do custo de produção permite calcular um indicador econômico fundamental para o planejamento e a tomada de decisão, que é o ponto de equilíbrio, o qual determina a quantidade mínima a ser produzida para cobrir os custos totais de produção (fixos + variáveis). É determinado pela equação (e), a partir da divisão dos custos fixos da atividade pecuária de cria, somados aos custos de remuneração da terra e do capital pela diferença entre o preço de venda de uma unidade de produto (PU) e o custo variável de uma unidade $(\mathrm{CVu})$ de produto (Santos \& Marion, 1993; Bornia, 2002).

$$
\begin{aligned}
& \text { custo fixo + remuneração da } \\
& \text { terra e do capital }
\end{aligned}
$$

(e): ponto de equilíbrio $=$ econômico (PE) preço unitário (PU) - $(\mathrm{CVu})$

Tabela 1 - Estrutura do rebanho e sua equivalência em unidades animais (UA)

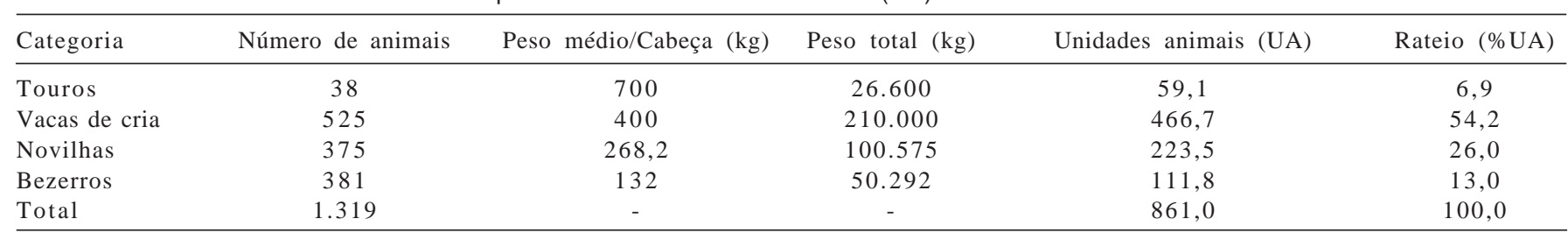


Segundo Sprott (1998), o cálculo do ponto de equilíbrio (Break-Even Costs) do bezerro auxilia os produtores de pecuária de cria na tomada de decisões estratégicas de manejo, além de planejar o presente e o futuro, pois possibilita determinar o preço mínimo de venda do bezerro para cobrir todos os custos de produção, além de estimar o custo máximo anual por vaca, a taxa de prenhez mínima necessária para cobrir o custo e, ainda, o peso mínimo ao desmame ou o preço de venda.

O método foi aplicado no sistema de produção descrito no Material e Métodos. Para isso foram fixados os principais parâmetros que influem na construção dos centros e no processo de custos. O período representativo de 12 meses foi empregado para considerar um ano pecuário correspondente ao período de julho a junho.

Constam na Tabela 2 os principais parâmetros produtivos adotados na simulação, sendo que as informações utilizadas foram baseadas em resultados de pesquisas em rebanhos de cria no Estado do Rio Grande do Sul (Barcellos, 1999; Lobato, 1999; Oliveira et al., 2006).

A produção total foi de $78.750 \mathrm{~kg}$ ( $\mathrm{n}^{\mathrm{O}}$ bezerros*peso médio ao desmame) e a eficiência do sistema, de $52,5 \mathrm{~kg} / \mathrm{ha}$ (produção total/área), constando somente da venda dos bezerros, excluídos os valores das vacas vazias de descarte.

O cálculo do custo de produção do bezerro, baseado no sistema de produção (Tabela 2), e os valores dos itens que constituem as despesas (Tabela 3) foram obtidos a partir de informações de mercado. É importante enfatizar que os valores finais obtidos têm a finalidade de aferir a eficiência do método e não gerar comparações com outros valores obtidos por pesquisadores ou demonstrados no próprio mercado. Isso porque é possível ocorrer grandes variações no resultado final, uma vez que cada propriedade rural apresenta valores diferentes conforme seu sistema de produção, grau de tecnificação e conseqüentes indicadores de produtividade.

Os gastos com reprodução, suplementação animal, pastagens e arrendamentos foram diretamente atribuídos aos centros que utilizam estes itens. Por exemplo, o total desembolsado no item de custo reprodução, $\mathrm{R} \$ 22.000,00$, refere-se à aquisição de reprodutores (centro de custo touros) e, despesas com inseminação artificial, referentes aos centros de custos novilhas de primeiro acasalamento e vacas de cria, na ordem de $\mathrm{R} \$ 16.000,00$, $\mathrm{R} \$ 3.000,00$ e $\mathrm{R} \$ 3.000,00$, respectivamente.

Com relação ao item de custo suplementação animal, o valor total de $\mathrm{R} \$ 20.000,00$ foi diretamente apropriado aos centros touros, vacas de cria, recria das novilhas e desmame dos bezerros, na ordem de $\mathrm{R} \$ 2.000,0, \mathrm{R} \$ 4.000,00$, $\mathrm{R} \$ 10.000,00$ e $\mathrm{R} \$ 4.000,00$, respectivamente.
A remuneração da terra, depreciação e dos impostos foram calculados de acordo com dados regionais, todos ajustados ao módulo de 1.500 hectares. O valor da remuneração do capital foi calculado com taxa anual de juros de 10\%. Para o cálculo da mão-de-obra, foi determinado que a propriedade possui três empregados fixos com custo de salários, encargos sociais e alimentação de R \$ 700,00/mês/ cada, o que totaliza $\mathrm{R} \$ 25.200,00$ /anuais.

Nota-se claramente que as vacas de cria representam os maiores custos dentro deste sistema de produção (Figura 4),

Tabela 2 - Indicadores de produção e produtividade em pecuária de cria para a Região Sul do Brasil

\begin{tabular}{lcc}
\hline Parâmetro & Unidade & Valores-Períodos \\
\hline Área & ha & 1.500 \\
Número de matrizes & Cabeça & 750 \\
Taxa de desmame & $\%$ & 70 \\
Número de bezerros & Cabeça & 525 \\
desmamados & $\mathrm{kg}$ & 150 \\
Peso ao desmame & $\mathrm{kg}$ & 78.750 \\
Produção total & $\mathrm{kg} / \mathrm{ha}$ & 258,31 \\
Carga animal & - & Set/Out/Nov \\
Época de parição & - & Abril \\
Mês de desmame & - & Abril \\
Mês de venda & &
\end{tabular}

Tabela 3 - Simulações dos custos em um sistema de produção em pecuária de cria

\begin{tabular}{lccc}
\hline Custo fixo & Valor (R\$) & Critério de rateio & \% Custo \\
\hline Impostos (ITR, CNA) & $6.110,00$ & UA & 3,2 \\
Seguros & $3.000,00$ & UA & 1,6 \\
Mão-de-obra & $25.200,00$ & UA & 13,3 \\
Depreciação (1) & $8.722,50$ & UA & 4,6 \\
Subtotal (2) & $43.032,50$ & & 22,6
\end{tabular}

Custos variável

\begin{tabular}{lccc}
\hline Reprodução & $22.000,00$ & Direto & 11,6 \\
Combustíveis & $12.000,00$ & UA & 6,3 \\
Suplementação animal & $20.000,00$ & Direto & 10,5 \\
Sanidade & $6.595,00$ & UA & 3,5 \\
Pastagem & $9.000,00$ & Direto & 4,7 \\
Manutenção & $5.000,00$ & UA & 2,6 \\
Arrendamento & $3.000,00$ & Direto & 1,6 \\
Administração & $3.000,00$ & UA & 1,6 \\
Outros & $5.000,00$ & UA & 2,6 \\
Subtotal (3) & $85.595,00$ & & 45,0 \\
\hline Custos de oportunidade & Valor & Critério de rateio & $\%$ custos \\
\hline Remuneração da terra & $49.500,00$ & UA & 26,0 \\
Remuneração do & $11.990,50$ & UA & 6,3 \\
capital investido & & & \\
Subtotal (4) & $61.490,50$ & & 32,3 \\
Custo desembolsado (5) & $119.905,00$ & & \\
Custo operacional (2+3 $) 128.627,50$ & & 100,0 \\
Custo total ( 2+3+4 ) & $190.118,00$ & & \\
\hline
\end{tabular}

$\mathrm{UA}=$ unidade animal. 
conseqüência do maior número de UA, representando 39,8\% da estrutura do rebanho e $54,2 \%$ das unidades animais recebendo maior porção dos rateios dos custos indiretos. Os custos com endectocidas e carrapaticidas adquiridos para o rebanho geral são utilizados e lançados em maiores quantidades neste centro de custo.

Após a obtenção do custo total da atividade no período, a próxima etapa foi alcançar o custo unitário do bezerro e o custo por quilo desmamado (Tabela 4). Segundo Santos \& Marion (1993), a determinação dos custos de produção por unidade produzida é de fundamental importância para a análise econômica de atividades agropecuárias. O custo unitário por bezerro e o custo por quilo desmamado foram determinados a partir de uma taxa de desmame de $70 \%$ com peso médio dos bezerros de $150 \mathrm{~kg}$.

Conforme Arruda (1993), o custo histórico do bezerro de corte macho desmamado, no Brasil, é de US\$112,82 (1,00 dólar $=2,50$ reais), o que representa um valor atual de $\mathrm{R} \$ 282,05$.

Segundo McGrann et al. (1993), sistemas gerenciais devem interligar o desempenho econômico e o produtivo. Dados de 88 rebanhos de cria referentes a 14 estados norteamericanos demonstraram correlações positivas entre o percentual de prenhez e a taxa de desmame com a rentabilidade e correlações negativas entre o custo anual de vacas

Tabela 4 - Simulação dos custos de produção de bezerros de corte

\begin{tabular}{lc}
\hline Parâmetro & Valor $(\mathrm{R} \$)$ \\
\hline Custo unitário do bezerro (CUB) & \\
Total & 362,13 \\
Operacional & 245,00 \\
Custo por quilo desmamado (C/kg) & \\
Total & 2,41 \\
Operacional & 1,63 \\
\hline
\end{tabular}

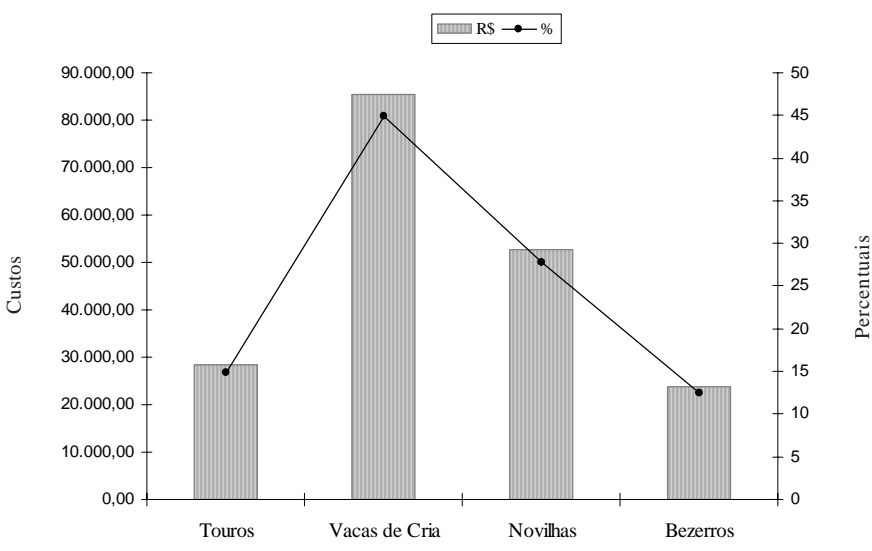

Figura 4 - Custos de produção e percentuais por centros de custos. de cria e a rentabilidade dos mesmos sistemas de cria. Não houve correlações positivas ou negativas entre peso ao desmame e rentabilidade, demonstrando que a maximização do desempenho reprodutivo deve ser o objetivo principal antes da busca por pesos elevados ao desmame.

O ponto de equilíbrio desta simulação resultou em 626 bezerros, considerando-se valores de $\mathrm{R} \$ 104.523,00$, $\mathrm{R} \$ 330,00$ e R \$ 163,04, respectivamente, para o custo fixo, somado à remuneração da terra e do capital, preço unitário e custo variável unitário. Contudo, para atingi-lo, seria necessário aumento de 13,5 pontos percentuais na taxa de desmame, passando de 70 para 83,5\%. Deve-se destacar que a análise deste indicador é importante para orçamentos, simulações e planejamento das atividades, posto que, no momento em que se inicia uma atividade, pouco poderá ser feito para alterar as relações de valores orçados. Fatores não controláveis, como limitações climáticas, podem prejudicar o planejamento inicial, diminuindo a rentabilidade esperada, por não atingir o ponto de equilíbrio.

\section{Conclusões}

O cálculo do custo de produção de bezerros de corte, pela utilização da metodologia dos centros de custos, mostrou-se aplicável em sistemas de produção com base na pecuária de cria.

Conhecer o custo de produção por intermédio de centros geradores de custos permite ao empresário rural compreender o impacto de determinados processos e/ou tecnologias sobre o sistema, especificamente no custo final do produto. Neste sentido, determinar o custo do bezerro de corte, bem como sua composição, é ferramenta essencial para uma pecuária de corte rentável e eficiente, diminuindo riscos e incertezas dentro de um mercado competitivo.

A continuidade de pesquisas relacionadas a melhorias organizacionais, buscando o aperfeiçoamento da apropriação de custos nas empresas pecuárias, possibilita comparações entre os resultados atingidos nos sistemas de produção. Ao mesmo tempo, fornece informações auxiliares para instituições de pesquisa, de natureza pública e privada, buscando a uniformidade e padronização dos métodos oriundos dos serviços estatísticos.

\section{Literatura Citada}

ARRUDA, Z.J. Considerações econômicas sobre a produção de bezerros de corte. Campo Grande: Embrapa Gado de Corte, 1993. 6p. (Documentos, 47).

BARCELLOS, J.O.J. Manejo integrado: um conceito para aumentar a produtividade dos sistemas de produção de bovinos de corte. 
In: LOBATO, J.F.P.; BARCELLOS, J.O.; KESSLER, A.M. (Eds.). Produção de bovinos de corte. Porto Alegre: EDIPUC, 1999. p.287-313.

BARCELLOS, J.O.J.; SUNE, Y.B.P.; SEMMELMANN, C.E.N. et al. A bovinocultura de corte frente à agriculturização no sul do Brasil. In: CICLO DE ATUALIZACAO EM MEDICINA VETERINÁRIA, 11., 2004, Lages. Anais... Lages: CAMEVUDESC, 2004. p.13-30.

BONACCINI, L. A. A nova empresa rural. Cuiabá: Sebrae-MT, 2002. 141p.

BORNIA, A.C. Análise gerencial de custos: aplicação em empresas modernas. Porto Alegre: Bookman, 2002. 203p.

CENTRO DE ESTUDOS EM ECONOMIA APLICADA - CEPEA; CONFERAÇÃO DE AGRICULTURA E PECUÁRIA DO BRASL - CNA. [2006]. Metodologia do índice de preços dos insumos utilizados na produção pecuária brasileira. Disponível em: <www.cepea.esalq.usp.br> Acesso em: 20/11/2006.

CORAH, L. The History of IRM and SPA. In: MORRIS, D.L. (Ed.) The veterinary clinics of North America: food animal practice. Philadelphia: 1995. p.191-198.

FIGUEIREDO, R.S. Sistemas de apuração de custos. In: BATALHA, M.O. (Ed.). Gestão agroindustrial. São Paulo: Atlas: 1996. p.381-464.

LOBATO, J. F. P. Considerações efetivas sobre seleção, produção e manejo para maior produtividade dos rebanhos de cria. In: LOBATO, J.F.P.; BARCELLOS, J.O.J.; KESSLER, A.M. (Eds.). Produção de bovinos de corte. Porto Alegre: EDIPUC, 1999. p.235-285.
LOPES, M.A.; CARVALHO, F.M. Custo de produção de gado de corte. Lavras: Universidade Federal de Lavras, 2000. 42p. (Boletim Agropecuário, 33).

MARTINS, E. Contabilidade de custos. 6.ed. São Paulo: Atlas, 2003. 390p.

McGRANN, J.; PARKER, J.; FALCONER, L. et al. Standardized Performance Analysis (SPA) - IRM-SPA Hand-Book Articles. Texas: Department of Agricultural Economics, 1993.

OAIGEN, R.P.; BARCELLOS, J.O.J.; CHRISTOFARI, L.F. et al. Custos de produção em terneiros de corte: uma revisão. Veterinária em Foco, v.3, n.2, p.169-180, 2006.

OLIVEIRA, R.L.; BARBOSA, M.A.A.F.; LADEIRA, M.M. et al. Nutrição e manejo de bovinos de corte na fase de cria. Revista Brasileira de Saúde e Produção Animal, v.7, n.1, p.57-86, 2006.

ROVIRA, J. Manejo nutritivo de los rodeos de cría en pastoreo. Montevideo: Hemisferio Sur, 1996. 288p.

SANTOS, G.J.; MARION, J.C. Administração de custos na agropecuária. São Paulo: Atlas, 1993. 141p.

SPROTT, L.R. Break-even costs for cow/calf producers. [1998]. Texas Agricultural Extension Service. TexasA\&M University Sistem. Disponível em: <http://animalscience.tamu.edu/ansc/ publications/beefpubs/L5200-breakeven.pdf> Acesso em: 10/5/2005.

VITORINO FILHO, L.C. Produção, gerenciamento, custos e comercialização na pecuária de corte atual. In: SOARES FILHO, C.V.; CAETANO, H. (Eds.). Curso de gerenciamento e custos na pecuária de corte. 2.ed. Araçatuba: Universidade Estadual Paulista, 2002. p.1-22. 